\title{
BMJ Open Variation in adverse drug reactions listed in product information for antidepressants and anticonvulsants, between the USA and Europe: a comparison review of paired regulatory documents
}

\author{
Victoria R Cornelius, ${ }^{1}$ Kun Liu, ${ }^{2}$ Janet Peacock, ${ }^{2}$ Odile Sauzet ${ }^{3}$
}

To cite: Cornelius VR, Liu K, Peacock J, et al. Variation in adverse drug reactions listed in product information for antidepressants and anticonvulsants, between the USA and Europe: a comparison review of paired regulatory documents. BMJ Open 2016;6:e010599. doi:10.1136/bmjopen-2015010599

\section{- Prepublication history} and additional material is available. To view please visit the journal (http://dx.doi.org/ 10.1136/bmjopen-2015010599).

Received 18 November 2015 Revised 4 January 2016 Accepted 6 January 2016

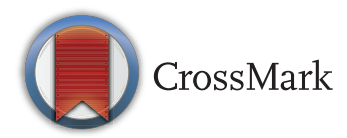

${ }^{1}$ Imperial Clinical Trials Unit, School of Public Health, Imperial College London, London, UK

${ }^{2} 4$ th Floor Addison House, Guy's Campus, King's College London, London, UK ${ }^{3} \mathrm{AG}$ Epidemiology and International Public Health, University of Bielefeld, Bielefeld, Germany

Correspondence to Dr Victoria R Cornelius; V.cornelius@imperial.ac.uk

\section{ABSTRACT}

Objective: To compare consistency of adverse drug reaction (ADR) data in publicly available product information documents for brand drugs, between the USA and Europe. To assess the usefulness of information for prescribers and patients.

Design: A comparison review of product information documents for antidepressants and anticonvulsants concurrently marketed by the same pharmaceutical company in the USA and Europe.

Setting: For each drug, data were extracted from the US Product Inserts and the European Summary of Product Characteristics documents between 09/2013 and 01/2015.

Participants: Individuals contributing ADR information to product information documents.

Main outcomes measures: All ADRs reported in product information sections 5 and 6 (USA), and 4.4 and 4.8 (Europe).

Results: Twelve brand drugs-24 paired documents -were included. On average, there were 77 more ADRs reported in the USA compared with in the European product information document, with a median number of 201 ADRs (range: 65-425) and 114 (range: 56-265), respectively. More product information documents in the USA reported information on the source of evidence (10 vs 5 ) and risk (9 vs 5 ) for greater than $80 \%$ of $A D R s$ included in the document. There was negligible information included regarding duration, severity, reversibility or recurrence of ADRs. On average, only $29 \%$ of $A D R$ terms were reported in both paired documents.

Conclusions: Product information documents contained a large number of ADRs, but lacked contextual data and information important to patients and prescribers, such as duration, severity and reversibility. The ADR profile was found to be inconsistently reported between the USA and Europe, for the same drug. Identifying, selecting, summarising and presenting multidimensional harm data should be underpinned by practical evidence-based guidelines. In order for prescribers to provide considered risk-benefit

\section{Strengths and limitations of this study}

- A paired review allowed for a perfect comparison to examine adverse drug reaction profiles between the USA and Europe.

- Adverse drug reaction data and document level data were extracted in duplicate.

- The degree of inconsistency between adverse drug reaction profiles, and lack of contextual information found in antidepressant and anticonvulsant drug documents, may not be representative of other therapeutic areas.

advice across competing drug therapies to patients, they need access to comprehensible and reliable ADR information.

\section{INTRODUCTION}

Prescribing choice between several available drug therapies is based on clinical efficacy with consideration given to the "perceived risk' of the drug. The perceived risk plays an increasingly important role in treatment decisions when there is little difference in efficacy or when comparative effectiveness among competing treatments is unknown. Robust information on the drug harm profile is therefore vital to facilitate the informed risk-benefit decisions made by patients and prescribers.

Drug harm profiles are established from various sources. Spontaneous reports of suspected adverse drug reactions (ADRs) rely on healthcare workers or patients recognising an association between a drug and an adverse event (AE). Observational studies and electronic healthcare records can be 
useful for identifying rare ADRs due to large sample sizes, but they are subject to a number of biases and often have no robust comparator.

Clinical trials have the potential to provide unbiased estimates of harm outcomes, but typical sample sizes result in uncommon ADRs remaining undetected.

Comprehensive information on drug harm in clinical trials is now routinely collected as a result of improved regulation since the early 1990s. Extensive research has demonstrated that the collection and reporting of harm data in peer-reviewed published clinical trials are both still substandard and, as a consequence, the data are not adequate to inform risk-benefit decisions nor sufficient to contribute to cost-effectiveness analysis. ${ }^{1-3}$ The main reasons for this are differing approaches in data collection, inadequate reporting of methodological details and selective harm outcome reporting. Poor quality harm data found in our systematic review of randomised trials for neuropathic pain led us to investigate other potential reliable sources of harm information. ${ }^{4}$ The regulatory application for marketing authorisation requires drug manufacturers to list all known drug harm in a 'product information document' that is primarily written for use by healthcare workers. ${ }^{5}{ }^{6}$ The aim of this regularly updated document is to present a comprehensive picture, combining data from all available sources, of the harm profile gathered throughout the development, testing and use of the drug. The document should include any known harm discovered by manufacturers, who are the marketing authorisation holders, as well as external parties. Consequently, this publically available document is uniquely placed to be an invaluable source of information for patients, healthcare workers, researchers and regulators. This document is called the 'summary of product characteristics' (SmPC), and is approved by the European Medicines Agency (EMA); and the US product insert (USPI) is approved by the US Food and Drug Administration (FDA). ${ }^{56}$

Previous research has demonstrated inconsistencies in information included in the product documents. Studies have reported discrepancies across countries for drugs marketed by the same pharmaceutical company regarding the number of ADRs, and differing risk estimates and number of patients in the safety sample. ${ }^{7-9}$ Other studies have found inconsistencies for the updating of contraindication labelling, pregnancy and lactation labelling, and advice on overdose in SmPCs compared to clinical management. ${ }^{10-12}$

The aim of our review was to examine the usefulness and relevance of ADR information-for antidepressants and anticonvulsants-contained in product information for prescribers and patients. We compared the content between the USA and Europe for drugs marketed in both regions by the same market authorisation holder, to assess consistency. While some variability would be anticipated due to differences in regulatory cycles between regions and construction of the documents by different company teams, we would expect that the ADR profile between paired documents would be similar, as it should be based on centralised safety data.

\section{METHODS}

This review involved antidepressant and anticonvulsant brand drugs identified in a previous systematic review of randomised control trials evaluating treatments of postherpetic neuralgia and painful diabetic neuropathy. ${ }^{4}$ The brand drugs included were those, concurrently marketed in the USA and Europe, with available product information documents (USPI and SmPC).

Documents were downloaded from September 2013January 2015 from the US FDA and EMA, respectively. ${ }^{13-15}$ The paired documents were chosen to ensure inclusion of the same dose and formulation, and downloaded at the same time.

Data were extracted from sections 5 and 6 in the USPI and sections 4.4 and 4.8 in the SmPC.

Regulatory guidelines from the FDA and EMA request that the manufacturers should report all ADRs, which are AEs where there is a reasonable possibility the drug has played a causal role, however, documents sometimes included the term 'adverse event' for which the accepted definition implies that the drug may not be causal. ${ }^{56}$ As it was often not clear whether the events were truly ADRs or AEs, a pragmatic decision to extract all harm events reported was made-hereafter referred to as ADRs. Justification for this decision was based on the guidance by the EMA, which specifies that 'adverse events, without at least a suspected causal relationship should not be reported' and the FDA guidance, which stated (reporting of) 'an adverse reaction not plausibly related to drug therapy should be avoided'. A summary of the reporting guidelines for the FDA and European Commission can be seen in online supplementary table A.

Data extracted included: all ADRs; risk estimates; study design; sample size; the criterion used to identify ADRs from all AEs recorded in a clinical trial; dictionary used for coding ADRs, whether information on recurrent ADRs was reported; information on onset and duration of ADRs. Document level data were extracted by three reviewers (KL, VRC and OS) in duplicate, using a customised and piloted spreadsheet. Any differences in interpretation were resolved through discussion. Information on individual ADR terms was extracted electronically into a spreadsheet by a single reviewer (KL) and then checked by a second reviewer (VRC). Duplicate ADRs within a document were removed and the greater risk estimate was kept. ADRs due to rapid withdrawal or interactions with other medications were excluded from the review.

As this is a descriptive study, appropriate measures of central tendency (mean, median) and dispersion (SD, range) were calculated for quantitative data, frequency and percentages for categorical variables. No significance tests were performed. The study protocol is available on request from the corresponding author. 


\section{RESULTS}

Nineteen anticonvulsant and antidepressant brand drugs were included as contenders for this review. Twelve of these were found to be concurrently marketed in Europe and the USA, with SmPC and USPI documentation available. The characteristics of the documents for the included drugs are listed in table 1 and all drugs identified from our previous review are listed in online supplementary table B.

On average, 77 more ADRs were reported in the US documents than in the European documents. The median numbers of ADRs were 114 (IQR 93, 150) and 201 (IQR 114, 262) in the European and US documents, respectively (table 2). The majority of the ADRs terms differed between documents, on average only $29 \%$ of the total number of ADRs were reported in both documents (table 3 ).

\section{Source of evidence}

Knowing the source of the evidence of the ADR report (clinical trial, observational study, spontaneous report) provides important contextual information as both the study design and data collection method will directly impact on the estimated risk of the ADR. ${ }^{16}{ }^{17}$ The source of the ADR report was specified more frequently in the US documents than in the European documents. Of the 24 documents ten US and five European documents reported the source of the ADR report for $80 \%$ or more of all ADRs listed in the document, and the majority were reported as originating from clinical trial data (table 2 and online supplementary table $\mathrm{C}$ ).

\section{Risk of an adverse drug reaction}

It is not possible to accurately estimate the risk of ADRs identified through spontaneous reports as the number of people who prescribed the drug is unknown. Crude estimates can sometimes be sought from sales or electronic health record data and can be used to calculate an approximate risk. ${ }^{18}$ The European Commission guidance recommends that this estimate be based on 'adequately designed study' data, and with zero events observed, suggests estimating the upper 95\% CI limit using $3 / \mathrm{X}$, where $\mathrm{X}$ represents the total sample size summed up across all relevant clinical trials and studies (see online supplementary table A). It was unclear for all documents how risks of ADRs originating from spontaneous reports were derived. Nine of 12 US and 5 of 12 European documents reported risks for $80 \%$ or more of all ADRs originating from clinical trials (table 2).

\section{Observation time}

The causal mechanism of an ADR is often time dependent and the absolute risk will depend on the duration of exposure, therefore, information on the observation period is necessary for interpretation. Knowledge of the observation period also reveals how much is known about long-term use of the drug. Eight US and one European

Table 1 Characteristics of drug product information documents

\begin{tabular}{|c|c|c|c|c|c|c|}
\hline Drug & Brand name & Company & $\begin{array}{l}\text { Document } \\
\text { origin }\end{array}$ & Formulation & Dose (mg) & $\begin{array}{l}\text { Date of } \\
\text { document }\end{array}$ \\
\hline \multirow[t]{2}{*}{ Carbamazepine } & Tegretol & Novartis & Europe & Tablets & 100 & $07 / 06 / 2013$ \\
\hline & & & USA & $\begin{array}{l}\text { Tablets/chewable tablets/ } \\
\text { suspension }\end{array}$ & $100-400$ & $15 / 02 / 2013$ \\
\hline \multirow[t]{2}{*}{ Gabapentin } & Neurontin & Pfizer & Europe & Hard capsules & 300 & 03/04/2013 \\
\hline & & & USA & Capsules/tablets/suspension & $100-800$ & $01 / 05 / 2013$ \\
\hline \multirow[t]{2}{*}{ Lamotrigine } & Lamictal & GlaxoSmithKline & Europe & Dispersible/chewable & 200 & $01 / 02 / 2013$ \\
\hline & & & USA & Dispersible/chewable & $25-200$ & 07/23/2012 \\
\hline \multirow[t]{2}{*}{ Oxcarbazepine } & Trileptal & Novartis & Europe & Tablets & 150 & $17 / 04 / 2013$ \\
\hline & & & USA & Tablets/oral suspension & $150-600$ & $02 / 07 / 2013$ \\
\hline \multirow[t]{2}{*}{ Pregabalin } & Lyrica & Pfizer & Europe & Hard capsules & 25 & $04 / 12 / 2013$ \\
\hline & & & USA & Capsules & $25-300$ & $01 / 06 / 2013$ \\
\hline \multirow[t]{2}{*}{ Topiramate } & Topamax & Janssen & Europe & Tablet & 100 & 03/06/2013 \\
\hline & & & USA & Tablet/sprinkle capsules & $25-200$ & 01/10/2012 \\
\hline \multirow[t]{2}{*}{ Zonisamide } & Zonegran & Eisai & Europe & Hard capsules & $25-100$ & $13 / 02 / 2014$ \\
\hline & & & USA & Capsules & $25-100$ & 24/01/2012 \\
\hline \multirow[t]{2}{*}{ Clomipramine } & Anafranil & Novartis & Europe & Capsules & 50 & $10 / 07 / 2012$ \\
\hline & & & USA & Capsules & $25-75$ & $26 / 10 / 2012$ \\
\hline \multirow[t]{2}{*}{ Duloxetine } & Cymbalta & Eli Lilly & Europe & Capsules & $30-60$ & $15 / 07 / 2013$ \\
\hline & & & USA & Capsules & $20-60$ & $01 / 10 / 2012$ \\
\hline \multirow[t]{2}{*}{ Fluoxetine } & Prozac & Eli Lilly & Europe & Hard capsules & 20 & $01 / 03 / 2013$ \\
\hline & & & USA & Capsules & $10-90$ & $01 / 07 / 2014$ \\
\hline \multirow[t]{2}{*}{ Venlafaxine } & Efexor/Effexor & Pfizer & Europe & Capsules & $75-100$ & $26 / 01 / 2015$ \\
\hline & & & USA & Capsules & $37.5-150$ & $01 / 12 / 2014$ \\
\hline \multirow[t]{2}{*}{ Phenytoin } & Epanutin/Dilantin & Pfizer & Europe & Oral suspensions/tablets & $30-100$ & 04/01/2013 \\
\hline & & & USA & Capsules/tablets & $30-100$ & $07 / 03 / 2014$ \\
\hline
\end{tabular}


Table 2 Summary of data reported by product information document

\begin{tabular}{|c|c|c|c|}
\hline Item & & $\begin{array}{l}\text { Europe } \\
\text { Median (IQR) } \\
\end{array}$ & $\begin{array}{l}\text { USA } \\
\text { Median (IQR) }\end{array}$ \\
\hline Adverse Drug Reaction & Number ADRs & $114(93,150)$ & $201(114,262$ \\
\hline \multirow[t]{3}{*}{ Data source of ADR report } & (1) Clinical trial & $3(1,84)$ & $172(58,256)$ \\
\hline & (2) Spontaneous report/other & $4(1,9)$ & $8(2,14)$ \\
\hline & (3) Unspecified & $88(1,112)$ & $9(1,35)$ \\
\hline Document level reporting & & n (\%) & n (\%) \\
\hline Documents reporting items for $>80 \%$ of clinical & (1) Number of participants & $2(17)$ & $8(66)$ \\
\hline \multirow{3}{*}{ trial ADRs } & (2) Risk estimates & $5(41)$ & $9(75)$ \\
\hline & (3) Risk estimates by severity & $0(0)$ & $1(8)$ \\
\hline & (4) Length of study & $0(0)$ & $3(25)$ \\
\hline \multirow[t]{2}{*}{ Is any information on ADR risk reported by: } & (1) Indication (yes) & $2(17)$ & $9(75)$ \\
\hline & (2) Dose (yes) & $0(0)$ & $4(33)$ \\
\hline \multirow[t]{2}{*}{ Did the document contain any information on: } & (1) Recurrent ADRs (yes) & $0(0)$ & $0(0)$ \\
\hline & (2) Duration of ADR (yes) & $0(0)$ & $1(8)$ \\
\hline
\end{tabular}

ADRs, adverse drug reactions; IQR, Interquartile range.

document contained information on the duration of the observation period for a couple of ADRs (see online supplementary table $\mathrm{C}$ ) but only three documents from the USA reported this information for the majority of the ADRs arising from clinical trials (table 2).
Duration, severity, recurrence and reversibility of an ADR The anticipated duration, severity and likelihood of recurrence of an ADR is important to patients and prescribers. Only one US document contained any information about duration of an ADR, four US documents

Table 3 Reporting of adverse drug reactions (ADR) by product information document and drug

\begin{tabular}{|c|c|c|c|c|}
\hline \multirow[b]{2}{*}{ Drug } & \multirow[b]{2}{*}{ USA } & \multicolumn{2}{|l|}{ Europe } & \multirow{2}{*}{$\begin{array}{l}\text { Proportion with } \\
\text { same ADR term }\end{array}$} \\
\hline & & Reported & Not reported & \\
\hline \multirow[t]{2}{*}{ Carbamazepine } & Reported & 75 & 89 & 0.36 \\
\hline & Not reported & 47 & - & \\
\hline \multirow[t]{2}{*}{ Gabapentin } & Reported & 89 & 28 & 0.20 \\
\hline & Not reported & 336 & - & \\
\hline \multirow[t]{2}{*}{ Lamotrigine } & Reported & 36 & 20 & 0.14 \\
\hline & Not reported & 205 & - & \\
\hline \multirow[t]{2}{*}{ Oxcarbazepine } & Reported & 47 & 42 & 0.18 \\
\hline & Not reported & 168 & - & \\
\hline \multirow[t]{2}{*}{ Pregabablin } & Reported & 88 & 91 & 0.24 \\
\hline & Not reported & 187 & - & \\
\hline \multirow[t]{2}{*}{ Topiramate } & Reported & 84 & 181 & 0.20 \\
\hline & Not reported & 164 & - & \\
\hline \multirow[t]{2}{*}{ Zonisamide } & Reported & 39 & 58 & 0.16 \\
\hline & Not reported & 147 & - & \\
\hline \multirow[t]{2}{*}{ Clomipramine } & Reported & 53 & 43 & 0.14 \\
\hline & Not reported & 272 & - & \\
\hline \multirow[t]{2}{*}{ Duloxetine } & Reported & 104 & 32 & 0.60 \\
\hline & Not reported & 37 & - & \\
\hline \multirow[t]{2}{*}{ Fluoxetine } & Reported & 50 & 61 & 0.32 \\
\hline & Not reported & 45 & - & \\
\hline \multirow[t]{2}{*}{ Epanutin } & Reported & 50 & 36 & 0.50 \\
\hline & Not reported & 15 & - & \\
\hline \multirow[t]{2}{*}{ Efexor } & Reported & 68 & 58 & 0.42 \\
\hline & Not reported & 37 & - & \\
\hline
\end{tabular}


presented some information on severity but the information was limited to only a few ADRs. None of the documents presented data regarding recurrence or reversibility (table 2 ).

\section{Identifying ADRs from AEs reports collected from clinical trials}

In clinical trials, many AEs will be recorded for each treatment and not all of these will be causally linked to the drug under investigation. Ideally, a signal detection method that is statistically underpinned should be used to flag signals of ADRs from all AEs reported in a clinical trial. None of the documents used a statistical method to flag a signal but nine US and three European documents reported the rule-based approach used. It is important to know what method has been applied as this will dictate the number and type of ADRs that are flagged. The full list of differing rule-based approaches used are reported in table 4 . It can be seen that rule-based methods were not the same in three paired documents and that seven US documents used multiple criteria that were used within the same document (table 4).

\section{Dictionary for coding AEs}

Medical terminology dictionaries are used to code $\mathrm{AE}$ terms with an aim to standardise reports. For only one drug was the dictionary used reported in both documents, and it was different in each (see online supplementary table D). Six US and three European documents specified the dictionary used.

\section{DISCUSSION}

One of the aims of the FDA and EMA guidance for developing product information documents is to promote the consistency of harm reporting across drugs. It would be expected that the harm profiles of a drug marketed by the same company should be similar in the US and European document with the only differences due to variability in regulatory recommendations. This study has identified a lack of consistency across paired documents in the number and type of harms reported, approaches to code harm terms and the availability of contextual information required for interpretation. Our results are in line with other studies that found a high number of discrepancies in ADRs between the USA and Europe across a range of differing therapeutic areas. ${ }^{7-9}$

Table 4 Rule-based criteria listed in documents, for selecting adverse reactions to report in document from all adverse events collected during a clinical trial

\begin{tabular}{|c|c|c|c|}
\hline Drug & Document & No & Criteria listed $^{*}$ \\
\hline Gabapentin & USA & 1 & $\begin{array}{l}\text { All AEs except those too general to be informative OR not reasonably associated with the } \\
\text { use of drug }\end{array}$ \\
\hline \multirow[t]{3}{*}{ Lamotrigine } & USA & 1 & $\begin{array}{l}\text { AEs from RCT except AEs that are too general to be informative or not reasonably } \\
\text { attributed to the drug }\end{array}$ \\
\hline & USA & 2 & AEs from $\mathrm{RCT}$ that were $>5 \%$ AND greater than placebo arm \\
\hline & USA & 3 & AEs from RCT with frequency between $2-5 \%$ AND greater than placebo arm \\
\hline \multirow[t]{2}{*}{ Oxcarbazepine } & Europe & 1 & AEs that were clinically meaningful post marketing reports \\
\hline & USA & 1 & AEs from $\mathrm{RCT}$ that were $\geq 2 \%$ AND the incidence was greater than placebo \\
\hline \multirow[t]{3}{*}{ Pregabablin } & Europe & 1 & All AEs that occurred at an incidence greater than placebo and in more than one patient \\
\hline & USA & 1 & AEs from $\mathrm{RCT}$ that were $\geq 1 \%$ AND at least numerically more than in the placebo group \\
\hline & USA & 2 & $\begin{array}{l}\text { AEs from } R C T \text { that were } \geq 2 \% \text { AND the } A E \text { in higher dose group that was } \geq 2 \% \text { the rate in } \\
\text { both the placebo and low dose groups }\end{array}$ \\
\hline \multirow[t]{3}{*}{ Topiramate } & USA & 1 & AEs from $\mathrm{RCT}$ that were $\geq 2 \%$ AND the incidence was greater than placebo \\
\hline & USA & 2 & AEs from $\mathrm{RCT}$ that were $\geq 1 \%$ AND the incidence was greater than placebo \\
\hline & USA & 3 & $\begin{array}{l}\text { All AEs except those too general to be informative OR those not reasonably associated } \\
\text { with the use of drug }\end{array}$ \\
\hline \multirow[t]{2}{*}{ Zonisamide } & USA & 1 & $\begin{array}{l}\text { All events included except those too general to be informative, trivial events or those not } \\
\text { reasonably thought to be associated with drug }\end{array}$ \\
\hline & USA & 2 & AEs from RCT that were $\geq 2 \%$ AND the incidence was greater than placebo \\
\hline \multirow[t]{2}{*}{ Clomipramine } & USA & 1 & $\begin{array}{l}\text { Commonly observed AEs associated with the drug and not seen at an equivalent } \\
\text { incidence among placebo treated patients }\end{array}$ \\
\hline & USA & 2 & AEs leading to discontinuation \\
\hline \multirow[t]{4}{*}{ Duloxetine } & Europe & 1 & Most common AEs reported \\
\hline & USA & 1 & AEs from $\mathrm{RCT}$ that were $\geq 5 \%$ AND twice the placebo rate \\
\hline & USA & 2 & AEs from $\mathrm{RCT}$ that were $\geq 2 \%$ in $\mathrm{RCT}$ \\
\hline & USA & 3 & AEs from $\mathrm{RCT}$ that were $\geq 5 \%$ in $\mathrm{RCT}$ \\
\hline \multirow[t]{2}{*}{ Fluoxetine } & USA & 1 & AEs from RCT that were $>5 \%$ AND at least 2 times greater than placebo \\
\hline & USA & 2 & AEs from RCT that were $\geq 2 \%$ AND the incidence was greater than placebo \\
\hline
\end{tabular}

${ }^{*}$ Criteria are from $9 / 12$ documents from the USA and $3 / 12$ from Europe, the other documents did not report any criteria by which the harms were selected for reporting in the document.

AEs, adverse events; RCT, randomised controlled trial. 
The lack of consistency could be in part due to differing rule-based arbitrary criteria used to identify ADRs from all AEs reported in a trial as these criteria even varied within a document. It was not possible for us to assess whether the trials contributing to both paired documents were identical, potentially adding further discrepancies. It is possible that the year of approval may be associated with lack of consistency; however, with only a few drugs included and low consistency across all drugs, we did not explore this aspect, but previous studies have examined this and found conflicting results. Eriksson et $a l^{7}$ reported that drugs approved after 2000 showed higher consistency, but Kesselheim $e t a l^{8}$ reported that length of time on the market was not associated with consistency.

The lack of consistency demonstrated in this study across matched drug documents raises questions as to whether information across a class of drugs produced by different manufacturers could ever be usefully compared. Despite this, risk-benefit comparisons, in which these documents play a fundamental role in informing prescribers knowledge of harm, are undertaken daily.

The differences in the number of ADRs found between paired documents of the same drug may not all be real differences in the harm profile, but could simply be differences in ADR coding and presentation. It has been shown that ADR summaries are dependent on the dictionary used and even when the same dictionary is used there is inter-observer variation due to coding conventions. ${ }^{19-21}$ With differing dictionaries used to code harm, data aggregated to different levels and lack of procedures reported, it was not possible for us to draw further conclusions within this study.

In general, the US documents contained more information on methodological aspects and contextual information needed to assess and interpret harm events, such as data source of ADR and information by indication. However, the additional volume of material made the overall harm profile harder to absorb than information in the European documents. This contrasting approach of reporting ADRs in either insufficient or excessive detail has previously been raised by Kesselheim et al. ${ }^{8}$ The guidance from the EMA and FDA state that harm information should be 'clear and readily accessible'. ${ }^{5} 6$ Better ways to prioritise and present harm data are required to enable patients and prescribers to undertake informed risk-benefit decisions.

Current clinical practice may often be too reliant on prescribers drawing on personal experience, knowledge from a colleague or abbreviated ADR summaries available in prescribing handbooks. Most of the product documents included in this review reported more than 100 ADRs, with one document listing over 400. Studies in different therapeutic areas have also reported similar high numbers, with Kesselheim $e t a l^{8}$ reporting a median of 105 ADRs for 20 top-selling drugs across four countries, Eriksson $e t a l^{7}$ reporting 4003 ADRs in 40 drugs across two countries, and Duke $e t a l^{22}$ reporting a median of 49 ADRs across 5602 drugs and 10\% having greater than 150
ADRs reported. With such large numbers of ADRs reported and no information provided on severity, duration or recurrence, it is questionable how useful the information in these documents is. In general, the US documents contained a larger number of ADRs and it was often unclear if these harm events were truly ADRs rather than AEs. It is possible that the over-inclusion of many AEs is made to minimise the risk of litigation since the manufacturers of the brand drug are held legally responsible if these are not reported. ${ }^{23}$ However, the overinclusion of AEs will make the absorption of pertinent harm information harder for prescribers and patients. More rigorous guidance underpinned by empirical evidence is needed to reduce current uncertainty around what ADR information should be included and how it should be summarised and presented.

The wide risk categories predominantly used in the European documents should be reviewed. Adverse reactions are placed into categories such as 'very common' $(>1 / 10)$ or 'common' $(>1 / 100$ and $<1 / 10)$. While the purpose of these risk categories may be to assist readers in assimilating a large volume of harm information, they are too vague to be useful for serious ADRs. ADRs such as angle-closure glaucoma, rhabdomyolysis, ataxia and arthralgia are categorised as 'common', implying the risk could be anywhere from 1 in 100 to 1 in 10 . It is difficult to see how such an estimate can be useful in informing a risk-benefit decision especially in the absence of any information on severity, duration or reversibility. Instead, it may be preferable, where possible, to provide point estimates of risk with an indication of precision for lifethreatening events or events that significantly impact a patient's quality of life. In contrast, wide risk categories for ADRs with minimal impact on quality of life or physical health, such as 'yawning', may be sufficient.

All antidepressant documents included a warning for suicidal events with anticipated time to onset. No other information regarding onset, duration or recurrence was included for any other ADR. A patient may be willing to risk the occurrence of tinnitus or peripheral vision loss if the condition resolves but not if the duration is excessive and recurring.

Current guidance for clinical trials in the published literature has existed since $2004,{ }^{24}$ but has made little impact on the quality of harm reporting. ${ }^{1-3}$ This present review also found that data from trials were inadequately summarised and reported, and, notably, differed across paired documents of the same drug. Aagaard and Hansen $^{9}$ found that the sources of discrepancies across documents were primarily from information based on clinical trials.

Bringing together many sources of disparate information from various locations is technically problematic. An ambitious new initiative with the aim of collating information from a variety of sources (spontaneous reports, published literature, product documents and observational data) has been launched, but it is still in its infancy and its effectiveness is as yet unknown. ${ }^{25}$ There are initiatives 
to rank drugs for risk of a specific drug harm such as drug-induced arrhythmias (http://www.CredibleMeds. org, http://www.BrugadaDrugs.org), but these are lacking an overall harm profile. While the product information document is written with a focus on providing information to healthcare workers, we believe this publically available document is uniquely placed to be an invaluable source of information for patients and researchers. It is the only source that contains unpublished evidence held by the pharmaceutical company and includes all available evidence from clinical trials, post-authorisation safety studies and spontaneous reporting. What ADRs should be included and how to usefully present these multidimensional data to be informative to patients and prescribers requires further consideration.

Several studies have reported that patients would like more information on 'side effects', believing that full disclosure of side effect information would help them make more informed treatment decisions. ${ }^{26} 27$ Many studies have shown that giving patients more information does not lead to an increase in the reporting of 'side effects' ${ }^{28}{ }^{29}$ A recent review showed that patients have a tendency to underestimate their risk of harm. ${ }^{30}$ But there is evidence that when patients have been presented with harm leaflets that lack numerical information, they were more likely to overestimate their risk. ${ }^{31} 32$ It is a statutory requirement for all drug manufacturers to include Patient Information Leaflets (PILs) as an insert in the medicine package. A review of the effectiveness of PILs found that patients thought them to be poor quality in terms of layout and content, and considered that they did not help increase knowledge to allow informed risk-benefit decision-making. ${ }^{33}$

While it is clear that all serious and unexpected ADRs should be reported, it is also important to know the true risk of common and anticipated ADRs, as they have costbenefit consequences and can significantly impact on a patient's quality of life. In a trial, many hundreds of AEs may be recorded and a decision of what should be reported has to be made. Currently, common harm outcomes are usually selected by means of an arbitrary rulebased criterion such as 'an $\mathrm{AE}$ that occurs in at least $2 \%$ of patients and is twice the placebo rate'. Using this type of criterion leads to flagging the most frequent but not necessarily the most important ADRs from a patient or healthcare provider perspective.

It has previously been proposed that consistency in harm information from trials in the published literature could be improved by developing a set of 'core outcomes' to be reported by drug class based on the principle proposed for effectiveness studies (http://www. comet-initiative.org). ${ }^{2}$ These 'core outcome sets' are the agreed minimum outcomes that should be reported, and are developed through a consensus process that includes all key stakeholders. A particularly common issue pertinent to harm profiles concerns the absence of information for a particular harm. It can never be clear whether this is simply because it was not reported (below the threshold of a rule-based criterion) or no events were observed. To reduce the inconsistency demonstrated in this review, we would endorse development of core 'harm' outcome sets by drug class to be reported in addition to all serious and unexpected ADRs.

How harm data are collected has an important impact on the type and the number of events recorded. ${ }^{17} 24$ While we have not specifically explored this issue in the present study, it is clearly vital, and more attention should be paid to methods used to collect and record AEs.

This review highlights a number of weaknesses in harm information contained in product descriptions

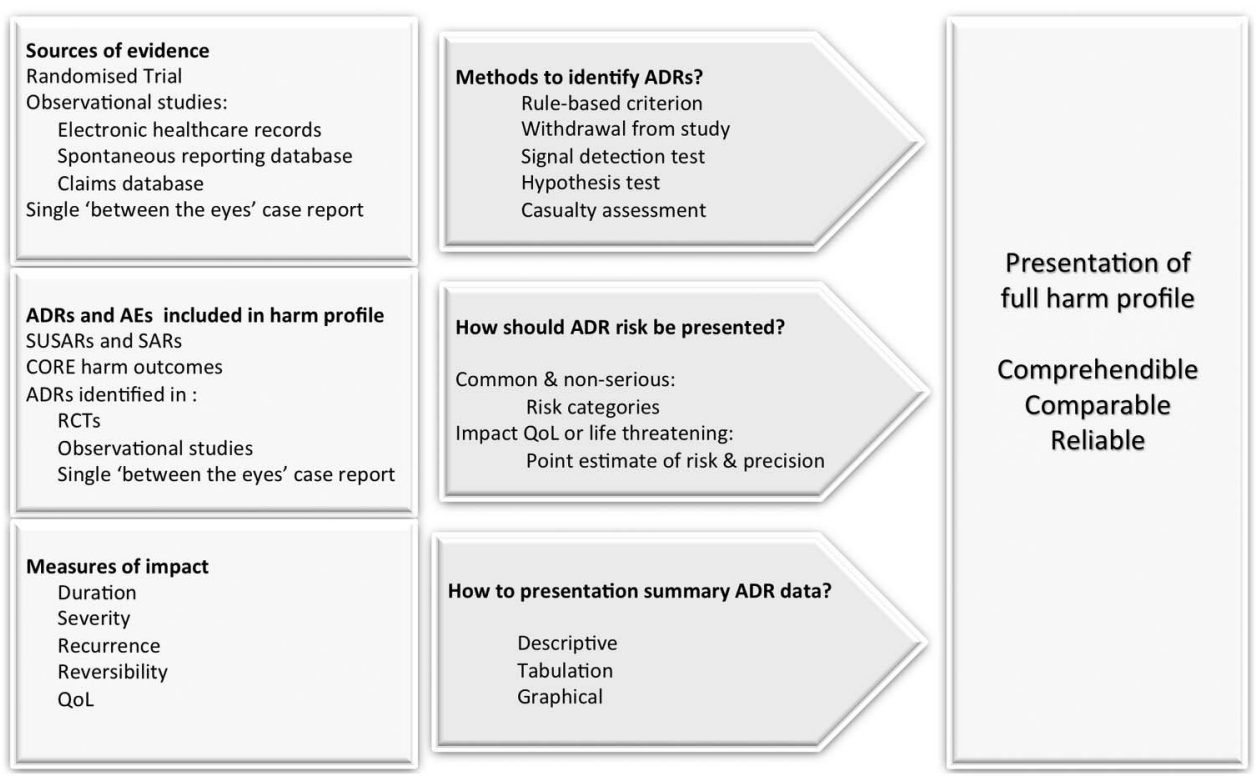

Figure 1 Overview of issues to address in selection and presentation of harm information from clinical studies. ADRs, adverse drug reaction; AEs, adverse event; QoL, quality of life; RCT, randomised controlled trial; SARs, serious adverse reaction; SUSARs, suspected unexpected serious adverse reactions. 
that are also relevant to harm reporting in primary studies. We propose a conceptual framework to address these issues in figure 1.

\section{CONCLUSIONS}

Publically available drug product documents have the potential to be valuable and vital sources of harm information, but data included in these were found to be inconsistent and not usefully presented. Identifying, selecting, summarising and presenting multidimensional harm data should be underpinned by practical evidencebased guidelines. Prescribers and patients require reliable reporting of pertinent ADRs to enable them to undertake meaningful informed risk-benefit decisions across competing drug therapies.

Acknowledgements In memory of Kun Liu.

Contributors VRC and OS were involved in the conception/design of the work. VRC, KL and OS were involved in the acquisition of data. VRC and $\mathrm{KL}$ were involved in the data analysis. VRC and OS were involved in the data interpretation and drafting of the manuscript. All the authors were involved revising it critically for important intellectual content and final approval of the version to be published. VRC is guarantor.

Funding The research was supported by the National Institute for Health Research (NIHR) Biomedical Research Centre based at Guy's and St Thomas' NHS Foundation Trust and King's College London. The views expressed are those of the authors and not necessarily those of the NHS, the NIHR or the Department of Health. VRC, KL and JP were supported by National Institute for Health Research (NIHR) Biomedical Research Centre based at Guy's and St Thomas' NHS Foundation Trust and King's College London. OS was supported by University of Bielefeld.

Competing interests None declared.

Provenance and peer review Not commissioned; externally peer reviewed.

Data sharing statement No additional data are available.

Open Access This is an Open Access article distributed in accordance with the Creative Commons Attribution Non Commercial (CC BY-NC 4.0) license, which permits others to distribute, remix, adapt, build upon this work noncommercially, and license their derivative works on different terms, provided the original work is properly cited and the use is non-commercial. See: http:// creativecommons.org/licenses/by-nc/4.0/

\section{REFERENCES}

1. Ioannidis JP. Adverse events in randomized trials: neglected, restricted, distorted, and silenced. Arch Intern Med 2009;169:1737-9.

2. Cornelius VR, Sauzet O, Williams JE, et al. Adverse event reporting in randomised controlled trials of neuropathic pain: considerations for future practice. Pain 2013;154:213-20.

3. Maggi CB, Griebeler IH, Dal Pizzol Tda S. Information on adverse events in randomised clinical trials assessing drug interventions published in four medical journals with high impact factors. Int J Risk Saf Med 2014:26:9-22.

4. Sauzet O, Williams JE, Ross J, et al. The characteristics and quality of randomized controlled trials in neuropathic pain: a descriptive study based on a systematic review. Clin J Pain 2013;29:591-9.

5. Food and Drug Administration. Guidance for Industry- Adverse Reactions Section of Labeling for Human Prescription Drug and Biological Products-Content and Format. http://www.fda.gov/ downloads/drugs/guidancecomplianceregulatoryinformation/ guidances/ucm075057.pdf \& http://www.fda.gov/downloads/drugs/ guidancecomplianceregulatoryinformation/guidances/ucm075082.pdf (accessed 12/2015).

6. European Commission. A guideline on summary of product characteristics (SmPC). http://ec.europa.eu/health/files/eudralex/ vol-2/c/smpc_guideline_rev2_en.pdf (accessed 12/2015)

7. Eriksson R, Aagaard L, Jensen LJ, et al. Discrepancies in listed adverse drug reactions in pharmaceutical product information supplied by the regulatory authorities in Denmark and the USA. Pharmacol Res Perspect 2014;2:e00038.

8. Kesselheim AS, Franklin JM, Avorn J, et al. Speaking the same language? International variations in the safety information accompanying top-selling prescription drugs. BMJ Qual Saf 2013;22:727-34.

9. Aagaard L, Hansen EH. Adverse drug reaction labeling for atomoxetine, methylphenidate and modafinil: comparison of product information for oral formulations in Australia, Denmark and the United States. Curr Drug Saf 2013;8:162-8.

10. Garbe E, Andersohn F. Contraindication labelling changes in the United States and Germany. Eur J Clin Pharmacol 2007;63:87-93.

11. Warrer P, Aagaard L, Hansen EH. Comparison of pregnancy and lactation labeling for attention-deficit hyperactivity disorder drugs marketed in Australia, the USA, Denmark, and the UK. Drug Saf 2014;37:805-13.

12. Wall AJ, Bateman DN, Waring WS. Variability in the quality of overdose advice in Summary of Product Characteristics (SPC) documents: gut decontamination recommendations for CNS drugs. Br J Clin Pharmacol 2009;67:83-7.

13. Food and Drug Administration. USPI. http://www.accessdata.fda.gov/ scripts/cder/drugsatfda (accessed 07/2015).

14. European Medicine Agency SmPC. http://www.ema.europa.eu/ema/ index.jsp?curl=pages/medicines/landing/epar_search jsp\&mid=WCOb01ac058001d124 (accessed 07/2015)

15. Medicines \& Healthcare products Regulatory Agency. SmPCs. http:// www.mhra.gov.uk/spc-pil/ (accessed 07/2015).

16. Golder S, Loke YK, Bland M. Comparison of pooled risk estimates for adverse effects from different observational study designs: methodological overview. PLOS ONE 2013;8:e71813.

17. Ioannidis JP, Mulrow CD, Goodman SN. Adverse events: the more you search, the more you find. Ann Intern Med 2006;144:298-300.

18. Strom BaV, G. Identification of Mechanisms and Risk Groups. Drug Epidemiology and Post Marketing Surveillance. Springer, 2013; Section A; 14-15.

19. Brown DR, Brown EG, Moulvad TB. A comparison of two medical terminologies in coding and analysing clinical trial safety data. Int J Pharm Med 1997;11:85-9.

20. Schroll JB, Maund E, Gøtzsche PC. Challenges in coding adverse events in clinical trials: a systematic review. PLOS ONE 2012;7: e41174.

21. Maund E, Tendal B, Hrobjartsson A, et al. Coding of adverse events of suicidality in clinical study reports of duloxetine for the treatment of major depressive disorder: descriptive study. BMJ 2014;348: g3555.

22. Duke J, Friedlin J, Ryan P. A quantitative analysis of adverse events and "overwarning" in drug labeling. Arch Intern Med 2011:171:944-6.

23. Kesselheim AS, Green MD, Avorn J. Who is now responsible for discovering and warning about adverse effects of generic drugs? JAMA 2013;310:1023-4.

24. Ioannidis JP, Evans SJ, Gotzsche PC, et al. Better reporting of harms in randomized trials: an extension of the CONSORT statement. Ann Intern Med 2004;141:781-8.

25. Boyce RD, Ryan PB, Norén GN, et al. Bridging islands of information to establish an integrated knowledge base of drugs and health outcomes of interest. Drug Saf 2014;37:557-67.

26. Ziegler DK, Mosier MC, Buenaver M, et al. How much information about adverse effects of medication do patients want from physicians? Arch Intern Med 2001;161:706-13.

27. Nair K ; Dolovich L; Cassels A, et al. What patients want to know about their medications. Focus group study of patient and clinician perspectives. Can Fam Physician 2002;48:104-10.

28. Howland JS, Baker MG, Poe T. Does patient education cause side effects? A controlled trial. J Fam Pract 1990;31:62-4.

29. Lamb GC, Green SS, Heron J. Can physicians warn patients of potential side effects without fear of causing those side effects? Arch Intern Med 1994;154:2753-6.

30. Hoffmann TC, Del Mar C. Patients' expectations of the benefits and harms of treatments, screening, and tests: a systematic review. JAMA Intern Med 2015;175:274-86.

31. Peters E, Hart PS, Tusler M, et al. Numbers matter to informed patient choices: a randomized design across age and numeracy levels. Med Decis Making 2014;34:430-42.

32. Sinayev $\mathrm{A}$, Peters $\mathrm{E}$, Tusler $\mathrm{M}$, et al. Presenting numeric information with percentages and descriptive risk labels: a randomized trial. Med Decis Making 2015;35:937-47.

33. Raynor DK, Blenkinsopp A, Knapp P, et al. A systematic review of quantitative and qualitative research on the role and effectiveness of written information available to patients about individual medicines. Health Technol Assess 2007;11:iii, 1-160. 